\title{
DESCOBRIR O AFETO: Uma Proposta de Educação Emocional na Escola
}

\author{
Elisa Pereira Gonsalves Possebon ${ }^{1}$ \\ Fabricio Possebon ${ }^{2}$
}

\begin{abstract}
RESUMO
Este artigo apresenta os resultados da investigação sobre os impactos do programa de formação em educação emocional do Núcleo de Educação Emocional (Neemoc-UFPB), realizado na rede municipal de ensino na cidade de Queimadas-PB, Brasil. Elaborada a partir das percepções docentes, a pesquisa qualitativa produziu dados, mediante depoimento e questionário, e considerou como pressupostos teóricos os trabalhos de Mayer e Salovey (2012), Bisquerra (2000), Damásio (2017) e Possebon (2018), entre outros. Foram obtidos como resultados, a partir da percepção docente, um conjunto de evidências que indicam a potência da metodologia teórico-vivencial do curso de formação. Em síntese, a proposta da vivência emocional parece superar em eficiência as abordagens da inteligência emocional e da competência emocional.
\end{abstract}

Palavras-chave: Educação emocional. Escola. Aprendizagem. Práticas integrativas e complementares.

\section{DISCOVER THE AFFECTION: A PROPOSAL FOR EMOTIONAL EDUCATION AT SCHOOL}

\section{ABSTRACT}

This article presents the results of the research on the impact of the training program in emotional education of the Núcleo de Educação Emocional (Neemoc-UFPB), conducted in the municipal school network, in the city of Queimadas-PB, Brazil. Based on the teachers' perceptions, qualitative research produced data, through a testimonial and questionnaire, and considered as theoretical presuppositions the work of Mayer and Salovey (2015), Bisquerra (2000), Damásio (2017) and Possebon (2018), among others. We obtained as results, from the teacher's perception, a set of evidences that indicate the power of the theoretical-experiential methodology of the training course. In summary, the proposal of the emotional experience seems to overcome in efficiency the approaches of emotional intelligence and emotional competence.

Keywords: Emotional education. School. Learning. Integrative and complementary practices.

RECEBIDO EM: 9/4/2019

ACEITO EM: 17/6/2019

\footnotetext{
${ }^{1}$ Doutora em Educação pela Universidade Metodista de Piracicaba, Professora Titular do Centro de Educação da Universidade Federal da Paraíba onde coordena o Núcleo de Educação Emocional. Integra o Programa de Pós-Graduação em Ciências das Religiões. http://lattes. cnpq.br/5800314750536359. http://orcid.org/0000-0003-4597-504X.elisa.gonsalves@gmail.com

${ }^{2}$ Coordenador do Programa de Pós-Graduação em Ciências das Religiões do Centro de Educação da Universidade Federal da Paraíba. Doutor em Letras pela UFPB. Pesquisador do Núcleo de Educação Emocional do CE/UFPB. http://sigaa.ufpb.br/sigaa/public/programa/portal. jsf?id=1902. http://lattes.cnpq.br/2781959905615456. http://orcid.org/0000-0001-9418-8224. fabriciopossebon@gmail.com
} 
A reflexão sobre educação emocional remete, invariavelmente, ao primeiro artigo científico sobre inteligência emocional-IE, escrito por John D. Mayer e Peter Salovey em 1990 (NAVAS; BERROCAL, 2012). Após a popularização do tema a partir do trabalho de Daniel Goleman, assistimos à criação de diferentes programas de educação emocional que se irradiaram no mundo, especialmente nos Estados Unidos, Reino Unido e Espanha, e que trouxeram como tônica a ênfase na organização de um programa de integração curricular que contemplasse a relação entre cognição e emoção (ALZINA; GONZÁLES; NAVARRO, 2015). A partir de então, diferentes investigações científicas passaram a se ocupar da temática, concluindo pela existência de ampla evidência de que competências sociais e emocionais podem ser desenvolvidas por meio de ações escolares e extraescolares, envolvendo toda a comunidade escolar, incluindo as famílias (ALZINA; GONZÁLES; NAVARRO, 2015). Nesses termos, têm-se observado em escala mundial os benefícios dos programas de educação emocional, especificamente no que se refere à eficácia na prevenção de conflitos nas escolas e, consequentemente, na adoção de condutas pró-sociais que envolvem atitudes solidárias e cooperativas, diminuindo processos agressivos e discriminatórios.

No Brasil, as iniciativas públicas em termos de programas no campo da educação emocional ainda são tímidas. Estudos remetem para a importância e necessidade de "realização de mais pesquisas científicas sobre o tema no Brasil, tanto quantitativas quanto qualitativas, principalmente visando à aplicação da Inteligência Emocional em contextos organizacionais, educacionais e sociais" (GONZAGA; MONTEIRO, 2011, p. 231). Neste cenário, a criação do Núcleo de Educação Emocional (Neemoc) na Universidade Federal da Paraíba se distingue pela relevância de se constituir em um lugar acadêmico de produção científica sobre este campo de conhecimento, configurando-se também como um espaço institucional dedicado ao desenvolvimento teórico-metodológico da educação emocional. Este artigo tem como objetivo investigar, sob a perspectiva docente, os impactos do programa de formação continuada em educação emocional do Neemoc, instituído na rede pública municipal da cidade de Queimadas-Paraíba, durante os anos de 2017 e 2018.

\section{EDUCAÇÃO EMOCIONAL: Apontamentos Teóricos}

A educação emocional é um constructo que possui amplos referenciais tendo um marco teórico integrador que "reconhece as contribuições de outras ciências, integrando-as em uma unidade de ação fundamentada" (ALZINA; GONZÁLEZ; NAVARRO, 2015, p. 173), avançando no diálogo com diferentes saberes em busca de um estatuto epistemológico transdisciplinar. Neste ponto, o diálogo entre as ciências e as tradições é fundamental para que novas compreensões possam emergir.

A educação emocional pode ser definida como um processo de formação inespecífico orientado "para maximizar as tendências construtivas e minimizar as destrutivas" (BISQUERRA, 2000, p. 243). Considerar a educação emocional inespecífica significa, primeiramente, admitir a impossibilidade de precisar seus impactos no indivíduo. Estabelecendo uma metáfora podemos afirmar que, ao contrário de um remédio que tem um único princípio ativo para agir em determinada doença, a educação emocional operaria com múltiplos princípios ativos que atuariam de forma complexa, no ser como um todo. 
Nesses termos, ao se trabalhar a raiva, por exemplo, "mesmo que todo o planejamento esteja voltado apenas para as especificidades daquela emoção, a realização da atividade ocorrerá internamente na criança como um raio que vai se expandindo, invadindo todo o Ser, toda a sua inteireza" (POSSEBON, 2018, p. 15).

A educação emocional é uma atividade preventiva que objetiva desenvolver a capacidade do indivíduo de evitar o desencadeamento de problemas advindos de pensamentos autodestrutivos, de comportamentos problemáticos (que envolvem consumo de drogas e violência) e de estados patológicos (anorexia, depressão) (BISQUERRA, 2000). Nesse sentido, atua na melhoria dos vínculos, das relações entre os indivíduos a partir do autoconhecimento. Tal melhoria "somente pode se efetivar no desenvolvimento de habilidades sociais, o qual pode ter uma incidência sobre a vida familiar, o companheiro, os amigos, os colegas de trabalho, as relações sociais em geral. Todos são fontes importantes de bem-estar" (BISQUERRA, 2000, p. 245).

Os objetivos da educação emocional estão centrados na aprendizagem e aceitação das próprias emoções e sentimentos e, por conseguinte, decidir quais são as atitudes mais apropriadas "em determinadas circunstâncias, de maneira que as mesmas contribuam para uma interação social e pessoal construtiva, positiva, capaz de contribuir para a elevação da sua qualidade de vida" (GARCIA RETANA, 2012, p. 18-19). Assim, a educação emocional ocupa-se de diferentes aspectos que incluem "consciência emocional, regulação emocional, autoestima, assertividade, tolerância à frustração, controle da impulsividade, resiliência, fluidez, bem-estar, dentre outros" (ALZINA; GONZÁLEZ; NAVARRO, 2015, p. 267).

Nesse sentido, a educação emocional teria o propósito de contribuir para o desenvolvimento humano operando uma mudança essencial da educação afetiva para a educação do afeto: "Até agora a dimensão afetiva em educação ou educação afetiva tem sido entendida como educar colocando afeto no processo educativo. Agora se trata de educar o afeto, quer dizer, compartilhar conhecimentos teóricos e práticos sobre as emoções" (BISQUERRA, 2000, p. 245).

Assim, na condição de processo educativo, a educação emocional se realiza de forma contínua e permanente, ao longo da vida do indivíduo - "a educação emocional tem um enfoque do ciclo vital" (BISQUERRA, 2000, p. 243). Compreender que a educação emocional é um processo que se dá ao longo da vida acentua seu caráter sociocultural, para além do âmbito escolar. Assim entendido, educar emocionalmente "é uma tarefa que compete a todos, aos pais, em primeiro lugar, no interesse de seus filhos, em seu próprio interesse, e às instituições de todo tipo desde o ponto de vista social" (REDORTA; OBIOLS; BISQUERRA, 2016, p. 186).

À educação emocional, como campo de conhecimento, é atribuído um conjunto de discussões mais amplas sobre a formação do ser (POSSEBON, 2018), contempla vertentes específicas sobre Inteligência Emocional-IE e Competência Emocional-CE. Tais expressões podem ser compreendidas como abordagens possíveis do campo epistemológico da educação emocional, que ainda se figura como um constructo, como uma emergência teórica na própria contemporaneidade. Assim, é necessário distinguir os termos inteligência e competência, especificamente pela existência de tratamento in- 
diferenciado entre eles (FRAGOSO-LUZURIAGA, 2015 ). Após a apresentação de tal distinção será exposta uma nova sugestão de educação emocional, denominada Vivência Emocional - VE.

\section{a. Sobre a Inteligência Emocional}

Historicamente pode-se afirmar, de acordo com Fragoso-Luzuriaga (2015), que o constructo IE possui a seguinte periodização:

- Concepção de inteligência e emoção como conceitos separados (1900-1970): enfoque psicométrico da inteligência humana, quando se começa a criar instrumentos para medir o raciocínio abstrato.

- Precursores da inteligência emocional (1970-1990): marcada pelas contribuições de Mayer e Salovey, Howard Gardner e Robert Sternberg.

- Criação do conceito (1990-1993): remete ao período de publicação de artigos científicos de Mayer e Salovey sobre inteligência emocional, identificando a percepção emocional, regulação emocional e a utilização da inteligência emocional como três habilidades integrantes deste tipo de inteligência.

- Popularização do conceito (1994-1997): popularização do conceito em meios acadêmicos e não acadêmicos com a divulgação do best-seller de Daniel Goleman. Surgimento de modelos que conformam a inteligência emocional como competências, influenciados pelo enfoque comportamental-organizacional predominante nos Estados Unidos.

- Institucionalização do modelo de habilidades e investigação (a partir de 1998): refinamento da proposta de Mayer e Salovey sobre inteligência emocional, cujo modelo passou a constar de quatro habilidades: percepção e valoração emocional, facilitação emocional, compreensão emocional e regulação reflexiva das emoções. Criação de novos instrumentos de medição.

Autores do "artigo científico fundador da investigação sobre a inteligência emocional" (ALZINA; GONZALEZ; NAVARRO, 2015, p. 36), Mayer e Salovey (2012) representarão a inteligência emocional como a "atitude ou habilidade central para raciocinar com as emoções" (MAYER; SALOVEY, 2012, p. 37). Nesses termos, a inteligência é uma habilidade, isto é, uma capacidade aprendida mediante um esforço cognitivo, técnico e interpessoal, a fim de se obter um determinado resultado. Em outras palavras, a inteligência emocional pode ser compreendida como uma destreza que permite a percepção, compreensão e gerência dos sentimentos próprios e alheios, com o objetivo de alcançar novos níveis de satisfação, eficácia e hábitos mentais (FRAGOSO; CHAVES, 2012).

O modelo de Mayer e Salovey (2012) destaca quatro habilidades específicas: percepção, valoração e expressão da emoção; facilitação emocional do pensamento; compreensão e análise das emoções empregando o conhecimento emocional e regulação reflexiva das emoções para promover o crescimento emocional e intelectual. Tais habilidades estão dispostas em um modelo hierarquicamente estruturado que, nas palavras destes autores, configuram "desde os processos psicológicos mais básicos até os mais elevados, os processos psicologicamente mais integrados" (MAYER; SALOVEY, 2012, p. 32). 
Ter IE significa ter habilidade para lidar com as quatro habilidades identificadas por Mayer e Salovey (2012), que estão dispostos hierarquicamente e cujo nível mais alto seria o da regulação reflexiva. Cada ramo possui um conjunto de habilidades assim dispostas:

Quadro 1 - Representação do modelo de inteligência emocional de Mayer e Salovey

4. Regulação reflexiva das emoções para promover o crescimento emocional e intelectual

4.1 Habilidade para estar aberto aos sentimentos, tanto placentários como displacentários

4.2 Habilidade para atrair ou distanciar-se reflexivamente de uma emoção, dependendo de sua informação ou utilidade

4.3 Habilidade para monitorar reflexivamente as emoções com relação a si mesmo e a outros, tais como reconhecer se são claros, típicos, influentes ou razoáveis

4.4 Habilidade para regular as emoções em si mesmo e nos outros, reduzindo as emoções negativas e intensificando as placentárias, sem reprimir ou exagerar a informação que transmite

\section{Compreensão e análise das emoções empregando o conhecimento emocional}

3.1 Habilidade para identificar emoções e reconhecer relações entre as palavras e as emoções, tal como a relação entre gostar e amar

3.2 Habilidade para interpretar os significados das emoções e suas relações com seus respectivos estímulos desencadeantes, tal como tristeza e perda

3.3 Habilidade para compreender sentimentos complexos: sentimentos simultâneos de amor e ódio ou mesclados, tais como o temor como uma combinação entre o medo e a surpresa

3.4 Habilidade para reconhecer as transições entre as emoções, tais como a transição da ira à satisfação, ou da ira para a vergonha

\section{Facilitação emocional do pensamento}

2.1 As emoções priorizam o pensamento ao dirigir a atenção à informação importante

2.2 As emoções são tão intensas e disponíveis que podem ser geradas como ajuda ao julgamento e da memória sobre os sentimentos

2.3 O humor modifica a perspectiva do indivíduo desde o otimismo até o pessimismo, favorecendo a consideração dos múltiplos pontos de vista

2.4 Os estados emocionais estimulam o enfrentamento de forma específica cada problema assim como a felicidade facilita o raciocínio indutivo e a criatividade

\section{Percepção, valorização e expressão da emoção}

1.1 Habilidade para identificar a emoção nos estados físicos, sentimentos e pensamentos

1.2 Habilidade para identificar emoções em indivíduos através da linguagem, som, aparência e conduta

1.3 Habilidade para expressar emoções adequadamente e expressar as necessidades relacionadas com esses sentimentos

1.4 Habilidade para discriminar entre expressões de emoções precisas ou imprecisas, honestas ou desonestas

Fonte: Mayer; Salovey (2012, p. 33).

Ter IE significa ter habilidade para lidar com as quatro habilidades identificadas por Mayer e Salovey (2012), que estão dispostos hierarquicamente e cujo nível mais alto seria o da regulação reflexiva. Pode-se compreender a IE, portanto, como a habilidade para processar a informação emocional "e utilizar esta informação como um guia para o pensamento e para a conduta" (SARRIONANDIA; GARAIGORDOBIL, 2017, p. 111). Nesses termos, a IE pode ser compreendida como um conjunto de disposições comportamentais e de autopercepções acerca das próprias capacidades de identificar, processar e utilizar as informações que possuem elementos de ordem emocional. 
No que se refere à forma de organização, um programa de IE desenvolvido em San Sebastián, na Espanha, pode ser ilustrativo. Realizado com êxito, obtendo resultados que evidenciaram que o programa potencializou um aumento da inteligência emocional de adolescentes, notadamente no que se refere ao aumento da inteligência intrapessoal, interpessoal e o estado de ânimo, o programa contemplou 20 sessões de uma hora de duração, realizadas semanalmente, com módulos sobre autoconsciência, regulação emocional, estado de ânimo, comunicação e empatia.

De acordo com Sarrionandia e Garaigordobil (2017, p. 113):

Um exemplo de atividade é a de "Observadores", que tem como objetivos fomentar: (a) a capacidade de identificar e compreender emoções, analisar suas causas e consequências, e (b) a capacidade de empatia e de resolução de problemas emocionais. Para isso os alunos veem diferentes vídeos (empatia de um trabalhador com uma anciã que está sendo despejada, a felicidade de um homem por comer sua comida favorita, o enfado de uma menina porque seus amigos chegaram tarde em sua festa e a preocupação de uma mulher por problemas de alcoolismo do seu marido) e respondem a umas perguntas em pequenos grupos: Que emoções aparecem no vídeo? Por que fulano se sente assim? Quais são as consequências das emoções? Que faria você naquela situação? No debate são colocadas perguntas em torno das interações e emoções experimentadas. Por exemplo: É fácil identificar as emoções? O que você aprendeu?

As atividades de IE variam entre a identificação de expressões faciais associadas com as emoções (exercícios para ligar rostos de bonecos com o nome das respectivas emoções), a verificação da presença de determinadas emoções em situações da vida real, filmes ou fotografias, a discussão sobre semelhanças e diferenças entre as emoções, até a aplicação da técnica role-playing para coordenar melhor problemas interpessoais, entre outros. Com um conjunto extenso de propostas didáticas, a metodologia da IE repousa, no seu âmago, na teoria cognitivo-comportamental do ponto de vista psicológico e educativo, para colaborar com o desenvolvimento do autoconhecimento do indivíduo.

\section{b. Sobre a Competência Emocional}

Ao longo do tempo o conceito de inteligência tem sido questionado por estudiosos que o apontam como inadequado para o campo da educação. O termo competência é defendido por alguns estudiosos como mais apropriado por indicar um fazer que pode ser aprendido ou melhorado, posto que incluiria o nível de conhecimento emocional (o que se sabe), o nível de capacidade emocional (o que se pode fazer a partir do que se propõe) e o nível disposicional (o que se faz habitualmente) (ALZINA; GONZÁLEZ; NAVARRO, 2015).

Diferente dos programas de IE que estão voltados para a percepção, regulação e conhecimento sobre as emoções para alcançar uma destreza específica, as propostas pautadas pela lógica das competências emocionais acenam no sentido de acumular um capital de atuação destinado a ser transferido mediante uma ação concreta. Nesse sentido, a competência é compreendida como "a capacidade de mobilizar adequadamente o conjunto de conhecimentos, capacidades, habilidades e atitudes necessárias para realizar atividades diversas com certo nível de qualidade e eficácia" (BISQUERRA; ESCODA, 2007, p. 63). 
A noção de competência emocional (CE) está relacionada com a demonstração, por meio de uma ação concreta, de capacidades e habilidades promotoras de resultado positivo. As competências relacionadas com as emoções podem ser entendidas como um conjunto de "habilidades que permitem interagir com os demais de forma satisfatória, além de contribuir para a satisfação interna, a consecução de êxitos pessoais e profissionais, e a uma adequada adaptação ao contexto" (ORTS, 2009, p. 19).

As competências emocionais podem ser assim apresentadas:

\section{Quadro 2 - Competências Emocionais de acordo com Rafael Bisquerra}

\section{Consciência emocional}

1.1 Consciência das próprias emoções: capacidade de perceber com precisão os sentimentos e emoções da pessoa; identificá-los e rotulá-los.

1.2 Dar nome às próprias emoções: capacidade de usar o vocabulário emocional.

1.3 Compreender as emoções dos outros: capacidade de perceber com precisão as emoções e perspectivas dos outros.

\section{Regulação emocional}

2.1 Tornar-se consciente da interação entre emoção, cognição e comportamento: os estados emocionais afetam o comportamento e as emoções afetam a emoção; ambos podem ser regulados pela cognição (raciocínio, consciência).

2.2 Expressão emocional: capacidade de expressar emoções apropriadamente.

2.3 Capacidade de regulação emocional: os sentimentos e emoções devem ser regulados.

2.4 Competências de enfrentamento: capacidade de lidar com emoções negativas por meio do uso de estratégias de autorregulação que melhorem a intensidade e a duração de tais estados emocionais.

2.5 Competência para emoções positivas autogeradoras: capacidade de experimentar voluntariamente e conscientemente emoções para uma melhor qualidade de vida.

\section{Autonomia pessoal}

3.1 Autoestima: ter uma autoimagem positiva.

3.2 Automotivação: a capacidade de se tornar automotivado e emocionalmente envolvido em várias atividades de lazer pessoal, social, profissional, etc.

3.3 Atitude positiva: capacidade de automotivar e ter uma atitude positiva em relação à vida.

3.4 Responsabilidade: intenção de se envolver em comportamentos seguros, saudáveis e éticos.

3.5 Análise crítica de normas sociais: capacidade de avaliar criticamente as mensagens sociais, culturais e midiáticas relacionadas a normas sociais e comportamentos pessoais.

3.6 Procurar ajuda e recursos: capacidade de identificar a necessidade de apoio e assistência e saber como acessar os recursos disponíveis apropriados.

3.7 Autoeficácia emocional: capacidade de autoeficácia emocional: o indivíduo vê a si mesmo que sente o que quer sentir.

\section{Inteligência Interpessoal}

4.1 Dominar as habilidades sociais básicas: ouvir, cumprimentar, despedir-se, agradecer, pedir um favor, pedir desculpas, atitude de diálogo, etc.

4.2 Respeito pelos outros: intenção de aceitar e apreciar diferenças individuais e de grupo e valorizar os direitos de todas as pessoas.

4.3 Comunicação receptiva: capacidade de atender aos outros em comunicação verbal e não verbal para receber mensagens com precisão.

4.4 Comunicação expressiva: capacidade de iniciar e manter conversas, expressar claramente seus pensamentos e sentimentos, tanto na comunicação verbal quanto não verbal, e demonstrar aos outros que eles foram bem compreendidos.

4.5 Compartilhar emoções: consciência de que a estrutura e a natureza dos relacionamentos são parcialmente definidas por: a) o grau de imediação emocional ou sinceridade expressiva; e b) o grau de reciprocidade ou simetria no relacionamento.

4.6 Comportamento pró-social e cooperação: capacidade de esperar mudança; compartilhar em situações diádicas e de grupo; manter atitudes de bondade e respeito pelos outros.

4.7 Assertividade: manter um comportamento equilibrado, entre agressividade e passividade; isso implica a capacidade de dizer "não" claramente e mantê-lo, evitar situações em que alguém possa ser pressionado e retardar a atuação em situações de pressão até se sentir adequadamente preparado.

Habilidades de vida e bem-estar 
5.1 Identificação de problemas: capacidade de identificar situações que requerem uma solução ou decisão e avaliar riscos, barreiras e recursos.

5.2 Definir objetivos adaptativos: capacidade de definir metas positivas e realistas.

5.3 Solução de conflitos: capacidade de enfrentar conflitos sociais e problemas interpessoais, fornecendo soluções positivas e informadas para os problemas.

5.4 Negociação: capacidade de resolver conflitos em paz, considerando a perspectiva e os sentimentos dos outros.

5.5 Bem-estar subjetivo: capacidade de desfrutar conscientemente o bem-estar subjetivo e procurar transmiti-lo às pessoas com as quais interage.

5.6 Fluxo: Capacidade de gerar experiências ótimas na vida profissional, pessoal e social.

Fonte: BISQUERRA; ESCODA (2007, p. 9-12).

Nesse sentido, os conteúdos da CE versam sobre "o conhecimento das próprias emoções e dos demais; o manejo emocional, incluindo a automotivação consciente; a prevenção dos efeitos prejudiciais e potencialização de efeitos positivos das emoções, a aplicação dos conhecimentos nas relações interpessoais" (BISQUERRA, 2000, p. 247). Em outras palavras, a educação emocional pretende "potencializar o desenvolvimento das competências emocionais como elemento essencial do desenvolvimento integral da pessoa, com o objetivo de capacitá-la para a vida. Tudo isto tem como finalidade aumentar o bem-estar pessoal e social" (REDORTA; OBIOLS; BISQUERRA, 2016, p. 186).

A CE é compreendida, portanto, como a "capacidade de mobilizar adequadamente o conjunto de conhecimentos, capacidades, habilidades e atitudes necessárias para realizar atividades diversas com certo nível de qualidade e eficácia" (BISQUERRA; ESCODA, 2007, p. 3). Nesta perspectiva, a noção de competência constitui-se em um "capital ou potencial de atuação vinculado à capacidade de mobilizar-se ou colocar-se em ação" (BISQUERRA; ESCODA, 2007, p. 3).

Para ilustrar a organização de um programa de educação emocional baseado na lógica das competências, destaca-se o Programa de Educação Emocional CooperativoEdemco, aplicado com êxito em colégios de Madrid, Espanha, com crianças que estão matriculadas no primário. Este programa está organizado em dois módulos: o primeiro, denominado "reconhecimento de emoções" para desenvolver a identificação de expressões emocionais básicas em outras pessoas; e o segundo módulo, chamado de "compreensão emocional", que visa a melhorar a compreensão que as crianças têm das emoções, para favorecer o entendimento das situações associadas a elas. Todas as atividades foram realizadas de forma cooperativa, em que cada criança possui um papel ativo dentro do grupo: cada uma deve aprender a executar uma parte da tarefa em um grupo inicial (grupos de especialistas) para, posteriormente, aplicar e ensinar para os colegas o que aprendeu. (AMBRONA; LÓPEZ-PÉREZ; MÁRQUEZ-GONZÁLEZ, 2012). Foram aplicadas, durante duas semanas, oito sessões de educação emocional, observando-se que cada sessão tinha duração de uma hora e meia. Cada sessão se estruturou em três momentos: "identificação do conhecimento prévio da criança; explicação e realização da atividade correspondente; conclusão e síntese do aprendido para realizar uma atividade final para fixação dos conteúdos" (AMBRONA; LÓPEZ-PÉREZ; MÁRQUEZ-GONZÁLEZ, 2012, p. 44). 
As atividades de CE são amplas e podem ser apresentadas desde um questionário sobre a forma de como o indivíduo experimenta suas emoções até um conjunto extenso de dinâmicas de grupo em que se apresenta, por exemplo, uma situação-problema para reflexão e sugestões. No geral, trata-se de identificar e reconhecer as características das emoções envolvidas em determinadas situações a fim de oferecer respostas eficazes para solucionar problemas. Como na IE, são propostas que, do ponto de vista psicológico e educativo, se comunicam com a teoria cognitivo-comportamental.

\section{c. Sobre a Vivência Emocional}

Diferente das concepções de inteligência e competência para se trabalhar com as emoções, as noções que alicerçam e organizam o trabalho de educação emocional a partir do conceito de vivência estão baseadas nas contribuições de Damásio (2017), Possebon (2018) e Toro (2009).

As emoções não são abstrações ou mera informação, mas são "a experiência de determinados aspectos do estado da vida num organismo" (DAMÁSIO, 2017, p. 151). Isso significa que a vida que existe no corpo do indivíduo e que circula nas suas vísceras também oferece a matéria-prima do universo emocional e que é, no mínimo, limitante organizar uma proposta de educação emocional que reduza tal atividade a propostas meramente cognitivas, independente da sua corporeidade. Nas palavras de Damásio (2017, p. 42):

Os sentimentos são a revelação, em cada mente individual, do estatuto da vida no respectivo organismo, um estatuto expresso ao longo de uma amplitude que vai do positivo ao negativo. Uma homeostasia deficiente é expressa por sentimentos sobretudo negativos, ao passo que os sentimentos positivos expressam níveis homeostáticos apropriados e abrem oportunidades vantajosas aos organismos.

As emoções, na condição de experiências subjetivas de um corpo vivo, não se realizam de forma exclusivamente em um "painel de controle". Nesse sentido, Damásio é categórico: "O sistema nervoso não cria a mente por si só, mas sim em colaboração com o resto do organismo. Rejeito a visão tradicional do cérebro como origem única da mente" (2017, p. 45).

O aspecto vivencial diz respeito à intensidade da experiência com a vida - ele é a base para o desenvolvimento de um novo ser humano capaz de se vincular e manter relações de amor por si, pelo outro e pela natureza. Assim, compreendemos que a vivência é a possibilidade de instaurar novas aprendizagens de vinculação amorosa e de intensa conexão com a vida e, por isso, estão intimamente relacionadas com a experiência profunda, plena de significado.

Além disso, é importante destacar que a dimensão emocional se configura como uma das dimensões humanas, relacionada de forma integrada com as demais. A natureza humana deve ser compreendida em termos mais amplos, posto que "o Ser é uma completude, uma totalidade cujas partes se integram e estão implicadas, daí a impossibilidade de isolar um aspecto e trabalhar nele separadamente" (POSSEBON, 2018, p. 14). Em termos de síntese, adotamos a seguinte compreensão da constituição do Ser, tomada da tradição grega arcaica, com a tradução dos termos em Latim e Português: 
Quadro 3-As dimensões do ser

\begin{tabular}{|l|l|}
\hline \multicolumn{1}{|c|}{ Dimensão } & \multicolumn{1}{c|}{ Envoltório } \\
\hline dimensão anímica & psykhé, anima, alma \\
\hline dimensão intelectual ou mental & noûs, intelligentia, inteligência \\
\hline dimensão emocional & thymós, animus, ânimo \\
\hline dimensão pneumática ou vital & pneûma, spiritus, sopro \\
\hline dimensão somática ou corporal & sôma, corpus, corpo \\
\hline
\end{tabular}

Fonte: POSSEBON (2017, p. 18).

A proposta de educação assentada na abordagem da Vivência Emocional-VE é organizada para o bem-viver do indivíduo, a fim de trazer à tona sua grandeza interior que servirá de base para as relações humanas. Nesses termos, a Educação Emocional

é um processo de formação humana que envolve as dimensões física, vital, mental, emocional e espiritual do indivíduo, a partir da mobilização de diferentes emoções, tendo em vista a construção do bem viver - uma vida social assentada na solidariedade, na reciprocidade, na responsabilidade e na integralidade (POSSEBON, 2018, p. 16).

O poder reorganizador da vivência deve-se à qualidade única de surgir como a primeira expressão afetiva de nosso organismo, com sensações corporais fortes. As vivências constituem a expressão originária do mais íntimo de nós mesmos, anterior a toda elaboração simbólica ou racional (TORO, 2009). A Educação Emocional, para adquirir um potencial transformador, precisa se realizar por intermédio da vivência, sem a qual ficará limitada à cognição.

A proposta da Vivência Emocional está assim organizada:

Quadro 4 - Vivência Emocional de acordo com Elisa Gonsalves Possebon

\begin{tabular}{|c|}
\hline Perceber e acolher as emoções sentidas \\
\hline $\begin{array}{l}\text { 1.1 Reconhecer a informação que está associada com a emoção sentida. } \\
\text { 1.2 Verificar se a emoção é a central no processo ou se é uma emoção defensiva, que obscurece a que } \\
\text { é principal. } \\
\text { 1.3 Reconhecer no próprio corpo a emergência emocional. } \\
\text { 1.4 Identificar o estímulo que provoca a emoção. } \\
\text { 1.5 Tomar consciência das próprias emoções, do ponto de vista fisiológico e intersubjetivo. } \\
\text { 1.6 Descrever a emoção com palavras. } \\
\text { 1.7 Dar nome à própria emoção. } \\
\text { 1.8 Identificar se a experiência da emoção está sendo saudável ou desadaptativa. } \\
\text { 1.9 Avaliar se a emoção está sendo vivenciada de forma a proporcionar bem-estar. } \\
\text { 1.10 Reconhecer a qualidade da relação com as outras pessoas mediante o estímulo que provoca a } \\
\text { emoção. } \\
\text { 1.11 Tomar consciência da relação entre emoção, cognição e comportamento. }\end{array}$ \\
\hline Adquirir capacidade de diferenciar e manejar as emoções \\
\hline $\begin{array}{l}\text { 2.1 Representar mentalmente a emoção. } \\
\text { 2.2 Compreender as causas e as consequências da emoção vivenciada. } \\
\text { 2.3 Identificar os pensamentos destrutivos que acompanham o estado emocional. } \\
\text { 2.4 Ressignificar o estímulo. } \\
\text { 2.5 Despertar a própria voz interna qualificadora. } \\
\text { 2.6 Visualizar mentalmente uma situação alternativa, a nova resposta a ser alcançada. } \\
\text { 2.7 Modular a resposta diante do estímulo. } \\
\text { 2.8 Expandir a reação fisiológica vivenciada de forma saudável. } \\
\text { 2.9 Reconhecer e atribuir um significado à emoção. } \\
\text { 2.10 Distinguir a ação a ser implementada. }\end{array}$ \\
\hline
\end{tabular}




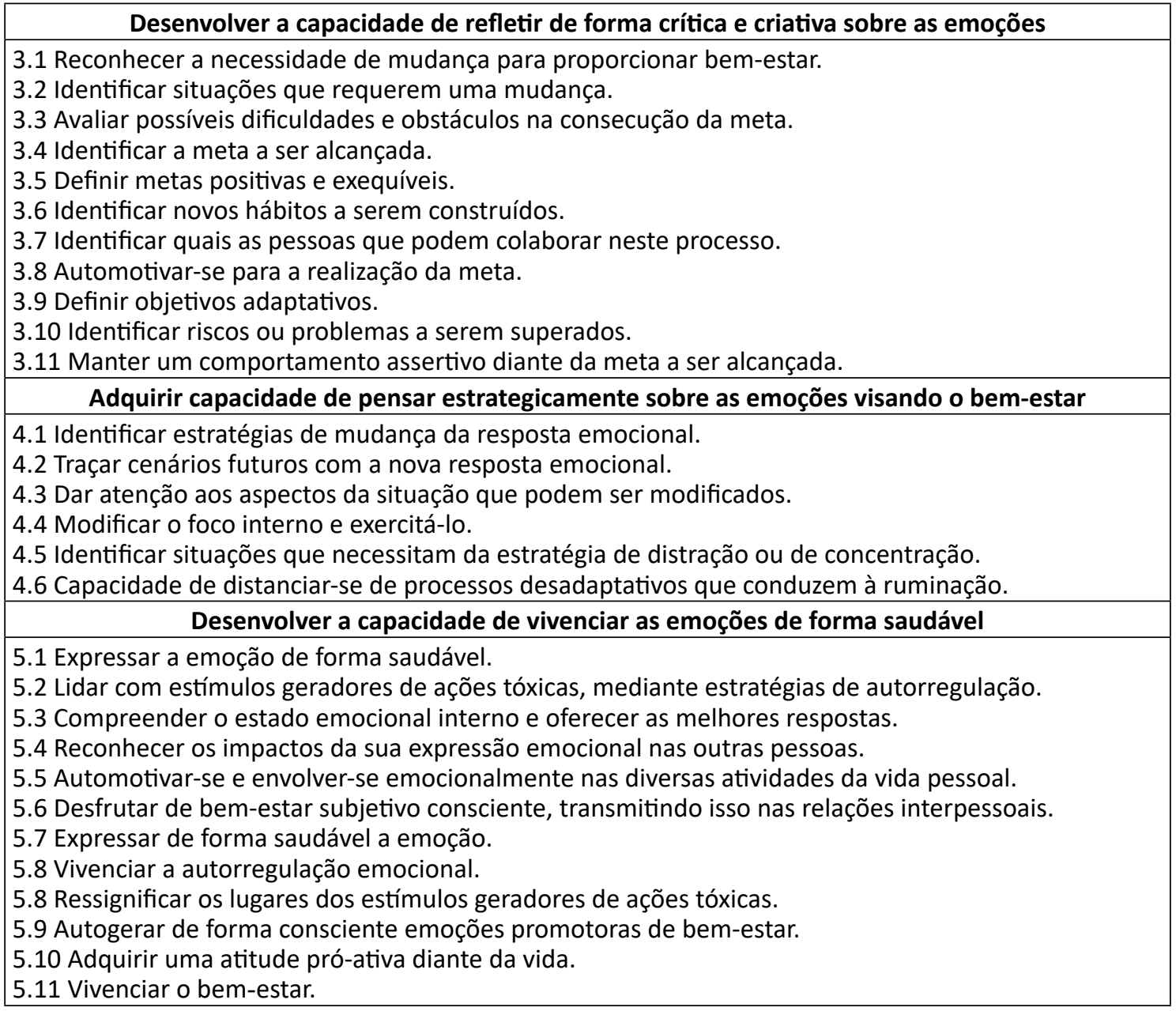

Fonte: POSSEBON, 2018.

O caráter vivencial remete para o pressuposto da integralidade. Ao vivenciar o aqui e o agora plenos de significados afetivos, o indivíduo é tocado em suas diferentes dimensões física, vital, mental, emocional, espiritual. O ser humano é uma inteireza e qualquer dimensão sua necessariamente afeta as demais, pois estão implicadas e influenciam-se mutuamente. Por conseguinte, ao trabalhar de forma integrativa a dimensão emocional, também estarão sendo mobilizadas as outras dimensões do Ser. Por exemplo, se em uma VE o tema é o da hostilidade, o indivíduo terá a oportunidade de conhecer a emoção em seus aspectos neurofisiológicos, comportamentais e psicológicos, e ainda vivenciar práticas que, além de colaborarem na reestruturação significativa do tema, contribuem para o desenvolvimento de atitudes mais afetivas.

A proposta de educação emocional, que possui como cerne a vivência, dialoga com Alzina, González e Navarro (2015), quando destacam várias estratégias para se atingir a regulação emocional, como a respiração, o relaxamento, a meditação, entre outras, no entanto, apenas o reconhecimento de que a meditação, por exemplo, seja uma estratégia de educação emocional, como sugere a $\mathrm{CE}$, não é suficiente. Em nosso entendimento, é fundamental aprofundar a temática na direção do reconhecimento de saberes da tradição que, no Brasil, remete para as Práticas Integrativas e Complementares-PICs. 
A VE tem como pressuposto a ideia de que os processos vivenciais produzem as mudanças comportamentais e que a mudança socioemocional ocorre mediante um processo complexo e sinérgico entre componentes viscerais (neurofisiológicos), vivenciais (emocionais) e cognitivos (mentais) (TORO, 2009). Além disso, quando se trata de transformações socioafetivas, a cognição por si só não é suficiente, ela não consegue atingir o núcleo da questão, posto que a natureza da aprendizagem afetiva está além de processos mentais. Neste sentido, a VE parte do entendimento de que somente aprendendo o mundo dos afetos é que os processos vitais e de vínculos podem ser reabilitados existencialmente. Sem a mobilização dos três componentes (visceral, vivencial e cognitivo), o aprendizado afetivo pode ficar debilitado, incompleto ou mesmo não ocorrer.

Não se trata, portanto, de utilizar a meditação ou técnicas de relaxamento como componentes motivacionais ou dinâmicas pontuais. A inclusão das PICs nos trabalhos de educação emocional a partir da VE significa o reconhecimento de uma matriz filosófica sobre a concepção do ser, sobre a sua integralidade, sobre a forma como ele se organiza e colabora com as aprendizagens afetivas e emocionais.

Assim, a proposta da VE é organizada contemplando exercícios próprios das Práticas Integrativas e Complementares (exemplo: yoga, meditação, biodanza, aromaterapia, cromoterapia). A estrutura metodológica da VE contempla múltiplos elementos que variam entre trabalhos individuais, em par ou em grupos mais amplos. As sessões possuem uma sequência de sete exercícios, organizadas didaticamente, para atingir um determinado objetivo e devem "ser encerradas com abraços fraternos - uma aprendizagem vital que precisamos fazer dentro ou fora da escola" (POSSEBON, 2018, p. 12).

A disposição didática da VE inclui necessariamente, e, nesta ordem, os seguintes exercícios (POSSEBON, 2018):

- dinâmica para conhecimento/reconhecimento de uma emoção;

- escrita sobre uma emoção (dicionário emocional ou livrinho da gratidão);

- exercício da ioga Bhrâmarî Prânâyâma (abelhinha);

- mudra, ásana (exercícios de gestos e posturas da ioga), meditação, gongoterapia (técnica que propõe a harmonização do ser integral, a partir da audição dos sons produzidos pelo gongo) ou mandalaterapia (técnica de colorir mandalas, cuja interpretação terapêutica depende das cores usadas e suas posições);

- exercícios de respiração (que podem incluir aromaterapia);

- exercícios de toque ou acariciamento (inspirados na Biodanza, exercícios de massoterapia e reflexologia podal);

- abraços.

Todas as sessões de VE são organizadas contemplando um conjunto de músicas, em sua maioria instrumentais, voltadas para relaxamento.

Cada sessão proposta da VE corresponde a um conjunto de etapas que contemplam habilidades a serem adquiridas no processo educativo de forma não linear. Não se trata de "treinar" ou "capacitar" pessoas para dar uma resposta eficiente; trata-se de trabalhar o ser integral a partir da harmonização de suas emoções, para que ele possa se colocar diante do outro, reconhecendo e aceitando a si mesmo, acolhendo o outro 
na diferença. A proposta é que, ao longo do tempo, com a regularidade das atividades de educação emocional, em sessões semanais, os resultados poderão ser obtidos e expressos positivamente mediante a ascensão a um estado de harmonização interior cada vez maior.

O quadro a seguir sintetiza, com termos-chave, os três olhares estudados:

Quadro 5 - Vertentes da Educação Emocional

\begin{tabular}{|l|l|l|}
\hline Inteligência emocional (IE) & Competência emocional (CE) & Vivência Emocional (VE) \\
\hline - inteligência e emoção se & - capacidade ou habilidade & - a emoção como experiência \\
distinguem; & para promover um resultado & de um estado da vida; \\
- atitude ou habilidade para & positivo; & - a vivência como possibilidade \\
raciocinar com a emoção; & - conhecimento das próprias & de aprendizagem, por ser uma \\
- destreza para gerenciar & emoções e dos demais, para o o & expressão original, anterior ao \\
sentimentos; & desenvolvimento integral da & racional; \\
- disposição cognitivo- & pessoa; & - práticas corporais \\
comportamental. & - respostas eficazes a partir & integrativas. \\
& do conhecimento. & \\
\hline
\end{tabular}

Fonte: Os autores.

\section{METODOLOGIA DA INVESTIGAÇÃO}

Considerando que o objeto da investigação se estrutura a partir da percepção dos docentes, optou-se pelo enfoque qualitativo pela possibilidade de interpretar os significados que os sujeitos fazem do mundo que os rodeia. Nesses termos, esta pesquisa pretendeu compreender o significado dos acontecimentos e interações dos docentes mediante os impactos de um curso de formação continuada, buscando, ao acessar o universo conceitual dos sujeitos pesquisados, compreender e interpretar as experiências socialmente construídas (BOGDAN; BIKLEN, 1994).

Atenta à produção de "significados das relações humanas a partir de pontos de vista" (STAKE, 2011, p. 25), esta investigação busca identificar os impactos educativos decorrentes do curso de formação em educação emocional promovido pela Seduc-Queimadas em parceria com o Neemoc. A busca das essências está contida nos dados verbais, advindos de descrições da experiência dos educadores sobre os impactos da educação emocional na sua vida pessoal e no seu trabalho docente. Tais descrições foram registradas mediante relatos pessoais e entregues à coordenação do Neemoc. A leitura dos dados permitiu apreender o sentido global e a organização de uma rede de significações dispostas em unidades, evidenciando as "presenças" ou "fenômenos" existentes nos dados de base (GIORGI, 2014, p. 407).

A cidade de Queimadas está localizada no interior da Paraíba e possui 47 escolas. Destas, 35 estão na zona rural, isto é 75\%. A rede municipal de ensino possui 8.012 alunos matriculados, dos quais 4.922 estão na zona rural, ou seja, $61 \%$ dos alunos estão matriculados na zona rural, enquanto $39 \%$ estão na zona urbana. A rede municipal possui 481 profissionais da educação, dos quais 297 atuam na zona rural e 184 na zona urbana, ou seja, $62 \%$ dos docentes estão lotados na zona rural. A média de alunos por docente é de 17 crianças (SEDUC, 2018). 
Do total de docentes da rede municipal de ensino, participaram da formação em educação emocional cem profissionais de educação, entre eles gestores, coordenadores e docentes, divididos em duas turmas de 50 participantes. A primeira turma congregou a equipe técnica e pedagógica das escolas, assim como gestores, enquanto que a segunda turma foi específica para docentes que estavam atuando diretamente em sala de aula. A formação foi realizada nos anos de 2017 e 2018. Para efeito desta pesquisa, foram incluídos como sujeitos desta investigação exclusivamente os docentes que estavam atuando diretamente em sala de aula no Ensino Fundamental.

Foram distribuídos 50 questionários para os professores que participaram da formação e que atuavam no Ensino Fundamental I, tendo sido devolvidos 33 - número este que configura o total dos sujeitos desta pesquisa. A aplicação foi realizada sem intercorrências e o tempo de resposta dos docentes ao questionário variou de 30 a 40 minutos.

De acordo com os dados, $59 \%$ dos sujeitos da pesquisa possuem entre 30 e 50 anos e $31 \%$ têm entre 20 e 30 anos. Todos respondentes são licenciados, e destes $69 \%$ possuem Pós-Graduação lato sensu ou stricto sensu. Quanto à experiência em magistério, $81 \%$ dos professores declararam possuir mais de 9 anos de experiência como docente, o que indica a busca individual de qualificação, posto que cursos desta natureza não são objeto de parceria com o município.

Os dados foram obtidos por meio de um questionário aplicado e da obtenção dos depoimentos.

O questionário, elaborado por pesquisadores do Neemoc, continha 63 questões fechadas, distribuídas em 8 blocos com os seguintes temas: planejamento das atividades de educação emocional; realização das vivências de educação emocional; recursos e estratégias utilizados nas vivências; relação professor-aluno; relação aluno-aluno; satisfação dos educadores; bem-estar docente. Além das questões fechadas constam no questionário duas questões abertas, uma que trata de um relato sobre algo que considera importante ter aprendido com a educação emocional e a outra que trata da descrição de algo que avalia como importante ter acontecido com seu alunado e que está relacionado com a educação emocional.

Considerou-se o questionário como uma primeira aproximação à temática investigada, tendo em vista que é um instrumento de coleta de dados que permite a descrição de características de um determinado objeto em se tratando da verificação de relações entre variáveis (RICHARDSON, 2011).

O outro instrumento de coleta de dados utilizado foram os depoimentos. A obtenção dos depoimentos escritos sobre os impactos da educação emocional foi realizada espontaneamente, por meio do grupo de Whatsapp dos docentes vinculados à formação continuada e também de forma induzida, mediante solicitação da coordenação do curso. Nas duas modalidades, buscou-se "deixar o sujeito exprimir abundantemente seu ponto de vista" (GIORGI, 2014, p. 398).

O grupo de Whatsapp criado pela coordenação converteu-se em um importante espaço de socialização de experiências, com um conjunto significativo de relatos sobre acontecimentos na vida escolar com a introdução da educação emocional. Foram so- 
cializados fotos, vídeos de aulas dadas e de alunos, todos com consentimento formal dos familiares. Pode-se perceber que o grupo de Whatsapp também se tornou um instrumento de motivação entre os docentes, que passaram a reconhecer e incentivar o trabalho do colega, instaurando um clima de solidariedade. Nesse sentido, o exercício da pesquisa proporcionou a instituição de um campo de reflexão dialógico, construindo um laboratório de práticas educativas inovadoras que deram visibilidade ao ofício docente, permitindo que colegas reconhecessem e demonstrassem confiança e gratidão.

Também foram coletados depoimentos escritos durante o curso de educação emocional e entregues à coordenação. Tais depoimentos referiram-se a fatos significativos que os professores associam às práticas de educação emocional. Os depoimentos foram compreendidos aqui como "uma obra (de arte) de seu autor. Ele diz algo além do que está escrito, ou seja, além daquilo que o autor intencionava dizer, pois seus significados serão presentificados na relação que o leitor estabelecer com ele" (MACÊDO, 1999, p. 38). Nesses termos, coloca como exigência para o pesquisador uma abertura para os saberes e sensibilidades do outro "que não é intelectual coisificador, mas vivencial-presentificador, ou seja, não coisificamos um depoimento escrito como objeto de estudo, mas vivenciamos e presentificamos para nós os seus significados" (MACÊDO, 1999, p. 38).

A análise dos dados foi realizada por meio de quatro passos: a) leitura, organização dos dados e síntese das questões principais que estão sendo percebidas pelo pesquisador, tratando-se de buscar uma significação global que "permite ver a forma como as partes são compostas" (GIORGI, 2014, p. 398); b) identificação das unidades de significação por meio do reconhecimento de que cada depoimento está repleto de referências ao cotidiano, possibilitando a discriminação dos sentidos; c) organização e enunciação dos dados brutos, quando o pesquisador examina e descreve novamente os dados, "de modo a tornar mais explícito o valor de cada unidade" (GIORGI, 2014, p. 400); d) síntese dos resultados mediante o reconhecimento da estrutura geral do fenômeno, a sua essência, que emerge por intermédio da identificação dos sentidos comuns e transversais entre os depoimentos, buscando verificar as relações que estabelecem entre si (GIORGI, 2014).

Foram cumpridas todas as formalidades e ações necessárias e exigidas para uma investigação rigorosa e ética, incluindo a confidencialidade e o consentimento da Secretaria da Educação, dos docentes, da escola e das famílias, bem como a aprovação do estudo e de aplicação do questionário pelo Comitê de Ética.

\section{A EDUCAÇÃO EMOCIONAL NA ESCOLA: Diálogo com os Dados Empíricos}

O trabalho de formação continuada constituiu o primeiro passo do programa de educação emocional. Tratou-se de formar docentes para trabalhar com a VE nas escolas municipais. Organizado a partir de um trabalho teórico-vivencial, a formação teve como pressuposto que os docentes não poderiam estar em situação passiva, tendo em vista que o trabalho de educar não se confunde com transferência de conhecimento. Como ensina Paulo Freire, diante de um curso de formação docente, é insuficiente que o professor assuma sua tarefa como um discurso sobre a teoria; a ausência da encarnação torna o trabalho de formação ineficaz (FREIRE, 2011, p. 47). 
A condição ativa e participativa na realização de um curso de formação inicia-se pela sua concretude. É no diálogo com o cotidiano que os docentes expõem seus saberes, colocando-se como interlocutores qualificados. Em outras palavras, a passividade só pode ser superada se o diálogo for mediado pelas encarnações possíveis, libertadoras e cotidianas.

A formação continuada em educação emocional teve, como ponto de partida, o docente como interlocutor. Na condição de seres sociais, com identidades pessoais e profissionais se fazendo de forma dialética e historicamente, cujas vivências emocionais estão inscritas em seus corpos, os professores foram compreendidos como "imersos numa vida grupal na qual partilham uma cultura, derivando seus conhecimentos, valores e atitudes dessas relações, com base nas representações constituídas nesse processo que é, ao mesmo tempo, social e intersubjetivo" (GATTI, 2003, p. 196). Nesse sentido, o trabalho de formação continuada esteve voltado para a melhoria das compreensões e práticas pedagógicas desenvolvidas na escola.

Nesta pesquisa verificou-se que a organização metodológica teórico-vivencial do curso de formação foi considerada diferente daqueles que já haviam participado, pois existia a prevalência de cursos que objetivavam apenas a transferência de conhecimentos. Os professores destacaram que os encontros de formação em educação emocional permitiram adentrar em um processo de autoconhecimento. Os relatos evidenciaram que o curso permitiu que os docentes pudessem ajudar a si, por terem alcançado uma nova compreensão de situações que estavam vivenciando, destacando a emergência de novos olhares para situações de conflito, ocasionando novas ações. Destacaram que o curso poderia ser compreendido como uma oportunidade para refletir sobre as próprias emoções e a forma como elas estavam afetando suas relações profissionais e pessoais. Os depoimentos também acenaram no sentido de que os docentes tornaram-se mais flexíveis com relação ao outro, mais pacientes, melhorando o vínculo estabelecido com outros indivíduos.

Considerando as habilidades retratadas no modelo de Mayer e Salovey (2012), observamos que as percepções docentes indicam uma correspondência com o alcance de habilidades de percepção, valorização e expressão da emoção, especificamente no que se refere à identificação de emoções e pensamentos diante de determinadas situações. Também foram registradas habilidades de compreensão e análise das emoções, como a capacidade de interpretar significados advindos das relações que estabelecem. Nesse sentido, a ação formativa, pela sua natureza teórico-vivencial, provocou o desenvolvimento de habilidades de inteligência emocional no professorado.

Compreende-se que quanto mais a ação formativa estiver mobilizando os indivíduos do ponto de vista sociocultural e emocional, mais condições de se efetivar uma mudança serão dadas: "Metaforicamente, diríamos que a alavanca tem que se integrar ao terreno para mover o que pretende mover" (GATTI, 2003, p. 197). Esta questão é importante porque em se tratando de uma formação em educação emocional, os próprios docentes precisavam ser educados emocionalmente para colaborar na geração de novos conhecimentos e ações em si e nos seus alunos. Sem se apropriar essencialmente do conteúdo da educação emocional não seria possível a irradiação da ação. Assim sendo, realizar o curso na concretude dos atos cotidianos permitiu respeitar o docente 
como sujeito autônomo e interlocutor competente, e foi condição necessária para a geração de mudanças na vida dos indivíduos. Isso posto, concordamos que os programas de formação que objetivam mudanças significativas no modo de agir das pessoas "só mostram efetividade quando levam em consideração as condições sociopsicológicas e culturais de existência das pessoas em seus nichos de habitação e convivência, e não apenas suas condições cognitivas" (GATTI, 2003, p. 197).

Partindo dos pressupostos discutidos até então foram estruturados 4 encontros de formação, cada um deles contendo uma carga horária de 12 horas, cumpridas em finais de semana ( 6 horas por dia), perfazendo uma carga horária total de 48 horas. Em todos os encontros foram distribuídos materiais pedagógicos que serviram como apoio para a aplicação do programa. De acordo com os sujeitos da pesquisa, os materiais distribuídos foram importantes e necessários para o desenvolvimento das vivências em sala de aula, tendo $100 \%$ afirmado que eles ajudaram em suas práticas pedagógicas.

A estruturação do curso em termos teórico-vivencial logrou êxito, tendo em vista que $93 \%$ dos sujeitos afirmaram que perceberam mudanças em si mesmos após o curso de educação emocional, destacando que estas mudanças estavam diretamente relacionadas à necessidade de se vincular de forma mais afetiva com as pessoas. Além disso, 91\% dos sujeitos afirmaram que percebem que suas ações cotidianas estão mais reguladas do ponto de vista emocional depois do curso. Tais mudanças estão relacionadas com uma atitude mais reflexiva, de busca de respostas sobre a natureza emocional de ações até então corriqueiras e que, de fato, denotavam a presença do medo, da raiva, da vergonha ou da culpa, especialmente, de maneira excessiva. Nesse sentido, o curso permitiu a criação de uma atmosfera de contemplação de si, permitindo inovações existenciais e recriações pessoais, por meio da adoção de novas posturas e escolhas.

Pelas suas condições sociais e históricas de existência, a escola pública tem se configurado como um contexto laboral difícil, "carregado de hostilidade, agressividade e atitudes pouco respeitosas" (ORTS, 2009, p. 134). A capacidade de autocontrole surge como muito importante neste contexto que exige, invariavelmente, uma necessidade de evitar a impulsividade e de lidar com emoções que envolvem níveis altos de ansiedade e de estresse. Nas palavras de Orts, "o autocontrole é um sinal de maturidade emocional ligado a um desenvolvimento da personalidade equilibrada e sã" (2009, p. 134).

É interessante destacar que todos os docentes afirmam que a formação em educação emocional teve impactos positivos na sua vida e que estão mais sensíveis com relação às questões de outras pessoas. Entre eles, $97 \%$ afirmaram que sentiram que sua paz interior foi expandida com as práticas de educação emocional vivenciadas. Os professores estabeleceram uma relação entre educação emocional e espiritualidade, tendo $86 \%$ registrado que a educação emocional colabora com a sua busca espiritual.

Ter a educação emocional como uma prática associada à expansão da paz interior é bastante relevante. Considerando que "a profissão docente é uma prática profissional de alto risco emocional que tende a gerar elevados níveis de ansiedade contra os quais o professor necessita se proteger para que suas resistências não sejam destruídas" (ORTS, 2009, p. 136), é possível estabelecer uma relação entre autocontrole e combate ao estresse na promoção do bem-estar subjetivo: "há que aprender a estar abaixo da 
linha de tensão com que se afronta cada problema, pois enfrentar um problema a partir da postura inicial de aceleramento e acaloramento reduz a capacidade neuronal de lidar com as emoções" (ORTS, 2009, p. 136).

A proposta foi estruturada tendo como foco a experimentação, por parte dos docentes, de um conjunto de vivências de educação emocional promotoras de conhecimento. A ideia de vivência é compreendida na perspectiva de Rolando Toro (2009), como uma "qualidade do originário", isto é, elementos naturais, próprios do instinto, que não estão sob o controle da consciência. Ao serem evocadas, as vivências possuem uma função reorganizadora do indivíduo, integrando-o de forma harmoniosa e com uma capacidade de reeducação afetiva. Nas suas palavras, trata-se de uma "cerimônia de transmutação" que se realiza por intermédio de um conjunto de exercícios mediados pela música possui poder de realizar uma mudança do plano atitudinal para o plano existencial (TORO, 2009).

Tendo em vista que foi oportunizado demonstrar a teoria na própria prática, experimentando durante a formação o método de educação emocional proposto e o desafio imediato da aplicação em sala de aula dos conhecimentos adquiridos, os docentes mostraram dificuldades no início da instituição da proposta. Ao longo do curso, no entanto, foi alcançando um nível melhor de destreza, sobretudo pelos resultados obtidos, com os docentes atribuindo essa segurança ao exercício cotidiano do fazer da educação emocional na escola. O fazer por si só, contudo, não poderia ser configurado como o elemento da competência: o sucesso da ação foi fundamental para que o docente pudesse se perceber como competente, como capaz de atuar neste campo.

Nesse sentido, a postura de segurança e a própria competência docente de trabaIhar com a educação emocional foi gerada e desenvolvida a partir dos próprios resultados obtidos com o alunado. Como afirma Paulo Freire, "a segurança com que a autoridade docente se move implica outra, a que se funda na sua competência profissional. Nenhuma autoridade docente se exerce ausente desta competência" (FREIRE, 2011, p. 89). Este é um dado importante porque coloca a competência docente não como um dado técnico, conquistado independentemente da sua aplicação. A emergência da competência se dá em curso e está diretamente relacionada com a satisfação obtida pelo resultado do trabalho.

Os docentes também registraram uma importante modificação com relação à questão da autoridade em sala de aula, posto que $96 \%$ afirmaram que perceberam que os alunos estão respeitando mais a sua autoridade. O reconhecimento da autoridade acontece ao mesmo tempo que a criança modifica a relação com o docente, criando cumplicidades na sala, como pedir silêncio para que o professor possa continuar sua explicação - o que até então parecia impossível, posto que o próprio aluno era o promotor da desordem - e até mesmo abraçando de forma espontânea o docente ao vê-lo chegar na escola.

A transformação experimentada pelos professores se estendeu para o vínculo estabelecido com os alunos. De acordo com os docentes, o olhar dispensado para os alunos foi modificado, uma vez que passaram a enxergá-los como um ser integral, possuidor de várias dimensões - físico, emocional, mental, vital e espiritual - e que esta compreensão possibilitou enxergar coisas que até então estavam obscuras, como 
a natureza de um comportamento agressivo. Adquirir uma capacidade de perceber as emoções e os sentimentos dos alunos permitiu aos professores, também, segundo os depoimentos, identificar as dificuldades de aprendizagem, muitas delas relacionadas à maneira como os alunos estão reagindo emocionalmente diante das dificuldades que encontram no seu cotidiano. Nesse sentido, pode-se colocar em tela a questão de que as dificuldades de aprendizagem dos alunos podem ser consideradas como um elemento flutuante e não como um dado estático, podendo estar relacionadas com um bloqueio emocional que impede a cognição de efetuar determinadas operações.

Apresentou-se como recorrente o fato de os docentes perceberem-se, ao longo da formação, como mais pacientes para ouvir os alunos, mais atentos às demandas deles, destinando-lhes inclusive um olhar mais afetivo. De acordo com os dados advindos do questionário, todos os docentes afirmaram que sua relação com os alunos se modificou após a formação em educação emocional, destacando-se que $97 \%$ perceberam que houve uma grande mudança. Entre eles, 93\% identificaram que suas atitudes ficaram mais afetivas com seus alunos após a introdução das aulas de educação emocional na escola, inclusive $97 \%$ afirmaram que passaram a ouvir mais os alunos. Todos os professores ressaltaram que, após a formação que tiveram, passaram a enxergar os alunos de uma forma diferente, e $97 \%$ registraram que essa mudança foi muito significativa. Segundo eles, o curso de educação emocional permitiu que eles pudessem refletir mais sobre as emoções dos alunos, e essa afirmação foi registrada de forma contundente por $96 \%$ dos docentes.

Além disso, os depoimentos relatam que a trajetória de cada aluno começou a fazer parte da percepção docente não como um dado burocrático, mas como uma fonte de informações preciosa que permitiu pensar o aluno na sua singularidade, ocasionando um novo posicionamento diferenciado diante dele. Assim, a vida do aluno passou a ser objeto de interesse do professor.

É interessante destacar que os docentes foram unânimes em afirmar que os alunos passaram a confiar mais neles, haja vista que $94 \%$ consideraram que isso aconteceu de forma significativa, sendo demonstrada de várias formas - desde pequenas cumplicidades cotidianas como pedidos de conselhos até a demonstração de mais credibilidade à atuação do professor. É interessante destacar que a confiança em pessoas possui três aspectos: intenções, compromissos e capacidades (BOS, 2010). Quanto à confiança em capacidades, diz respeito à questão técnica, isto é, não possui "sentido moral, mas faz com que eu não transfira certa tarefa, certa responsabilidade para alguém por ser da opinião de que essa pessoa não está suficientemente familiarizada com a situação" (BOS, 2010, p. 34). A confiança em intenções está relacionada com integridade e moral, e ocorre mediante a expectativa de que o indivíduo coloque "os interesses do grupo, da organização, o interesse comum simplesmente acima do seu próprio; que não faça mau uso de informações pessoais, que não empregue em assuntos privados suas liberdades burocráticas ou inerentes à função" (BOS, 2010, p. 34-35). Por fim, a confiança em compromissos está vinculada aos acordos relacionais que precisam ser cumpridos por uma questão ética. 
Considerando as reflexões de Bos (2010) sobre a questão da confiança, é possível perceber que a confiança em intenções foi desenvolvida a partir das aulas de educação emocional, isto é, os alunos começaram a ver o docente como uma pessoa íntegra, que estabelece uma relação humanizada, capaz de escutar, orientar e não julgar. Nesse sentido, pode-se concluir que a educação emocional, pelo conteúdo que mobiliza, permite o desenvolvimento de relações confiáveis entre professor e aluno, no sentido pessoal e profissional.

A felicidade, considerada uma meta a ser alcançada, também é tida como mais factível e exequível após o curso de formação, na percepção dos docentes. A valorização de itens como família, amigos, trabalho e das próprias conquistas passaram a ser reconhecidos como elementos fundamentais para o bem-estar subjetivo. Os docentes afirmam que técnicas empregadas como mandalaterapia, gongoterapia, reflexologia e biodanza permitiram a libertação de coisas do passado que eram sentidas como aprisionamentos, como obstáculos para seguir adiante com confiança.

Registros de mudança de comportamento de alunos que eram tidos como agressivos na escola são muitos. Ao serem indagados sobre a existência de atitudes discriminatórias durante as aulas de educação emocional, 78\% afirmaram a não ocorrência, entretanto $22 \%$ registraram comportamentos preconceituosos. Cabe dizer que $88 \%$ dos docentes afirmaram ter observado que os alunos passaram a desenvolver condutas mais afetivas com relação aos outros, enquanto que $75 \%$ deles relataram que os conflitos existentes entre os alunos diminuíram muito após a introdução das aulas de educação emocional na escola. É interessante destacar que os próprios docentes registraram uma surpresa durante a aula de educação emocional, tendo em vista que alguns alunos que a todo instante se agrediam fisicamente na escola não tiveram problemas em fazer os exercícios propostos e que envolviam atitudes carinhosas como abraços, acariciamento de cabelos, de mãos, toque nos pés, entre outros.

Tais depoimentos estão em consonância com a comprovação de existência da relação positiva existente entre a educação emocional e a prevenção de conflitos, "se dispõe de suficientes evidências científicas para confiar que, certamente, a inteligência emocional pode ser melhorada através de experiências educativas apropriadas, inclusive em períodos relativamente breves de tempo" (ALZINA; GONZÁLEZ; NAVARRO, 2015, p. 265). Tem-se conhecimento de que os programas de educação emocional colaboram no desenvolvimento do indivíduo, inclusive promovendo êxito acadêmico, pois além de contribuir para a melhoria da capacidade adaptativa das pessoas, tende a aumentar sua capacidade de autorregulação tendo em vista seu bem-estar (GARCIA RETANA, 2012).

De acordo com $87 \%$ dos docentes, os alunos demonstraram muito interesse em participar da aula de educação emocional, não tendo sido registrado nenhum tipo de comportamento alheio ou indiferente. É importante registrar que, segundo $90 \%$ dos professores, a maioria dos alunos deu feedback positivo durante as próprias vivências. A regularidade das vivências permite o desenvolvimento de significativas mudanças de comportamento. Os docentes informam que os exercícios realizados em sala e que são passíveis de serem repetidos individualmente, como práticas de ioga, de respiração e mudras (gesto das mãos) têm sido repetidos pelos alunos em casa, espontaneamente. Muitos alunos considerados mais agitados mudaram seu comportamento, demonstran- 
do uma atitude mais tranquila em aula e, indagados sobre a mudança, afirmaram estar repetindo o exercício denominado pranayama, chamado na aula de educação emocional de "abelhinha", devido ao som que é produzido, que lembra o zumbido da abelha. Os exercícios relacionados com a respiração, assim como os mudras foram indicados pelos professores como deflagradores de estados de concentração nas crianças. Eles avaliam que tais técnicas têm o poder de interferir na capacidade de atenção, facilitando a aprendizagem.

As mudanças percebidas pelos docentes nos seus alunos também são objeto de registro dos familiares em reuniões nas escolas. São muitos os relatos de que as crianças utilizam técnicas de respiração e meditação em casa.

O abraço, também exercício na educação emocional, constituiu uma fonte importante no trabalho da educação emocional. Docentes relatam que o abraço tem o poder de transformar as crianças, tendo em vista que muitos não possuem relações afetivas e cuidadosas em casa e que os exercícios de toque, acariciamento (mãos e cabelos), abraços, entre outros, são fundamentais para resgatar a estima das crianças e desenvolver atitudes afetivas de cuidado. As crianças demonstraram grande interesse em fazer uma atividade em que podem e devem cuidar do colega. Os professores são unânimes em afirmar que a educação emocional colabora para a melhoria da aprendizagem dos alunos, observando-se que $91 \%$ deles destacam que isso ocorre rapidamente e de forma perceptível.

Exercícios de toque e de acariciamentos propiciaram a vivência do cuidado ou, nas palavras de Orts (2009), a experiência de "rituais balsâmicos". Tais rituais são benéficos e funcionais, capazes de amenizar conflitos e confortar as pessoas, possuindo um "efeito balsâmico sobre nosso estado de ânimo e sobre o clima da classe" (ORTS, 2009, p. 162).

Em várias situações os docentes relacionaram um tipo de dificuldade em sala a uma emoção. Em se tratando da leitura oral, por exemplo, os docentes identificaram a partir das aulas de educação emocional que os alunos tinham vergonha de ler na frente dos colegas. É interessante destacar que todos os professores registraram que, após a introdução da educação emocional na escola, os alunos passaram a tirar dúvidas com mais facilidade, com $83 \%$ afirmando que isso passou a ocorrer de forma muito recorrente, o que revela uma superação da timidez ou vergonha. O que antes era compreendido como uma dificuldade na leitura propriamente dita foi identificada como uma emoção.

Sobre a questão da expressão oral também foi identificada uma relação entre ela e o medo. $O$ trabalho sobre a emoção do medo permitiu que muitos alunos vencessem a timidez e começassem a participar mais em sala de aula, inclusive tirando dúvidas, tipo de comportamento que não era tão frequente. $O$ enfrentamento do medo também colaborou com processos de elevação da estima das crianças, inclusive daquelas com deficiência. Depoimentos de docentes afirmam que as crianças passaram a se sentir mais aceitas e respeitadas, ao mesmo tempo que aprenderam o seu valor como indivíduo com direitos, independentemente da condição que tenha.

Nas palavras de Orts (2009, p. 151), "ainda que todo mundo tenha em algum momento de sua vida dúvidas sobre o seu valor, podemos falar de baixa estima quando essas dúvidas dominam nossa vida ao ponto de nos impedir de concentrarmos em nossos 
objetivos e tarefas". A estima baixa envolve indicadores como autocrítica rigorosa, ataques frequentes de ansiedade, mudanças de humor injustificadas, culpabilidade neurótica e reações exageradas (ORTS, 2009). Neste sentido, resgatar a estima dos alunos não significa apenas torná-los cognitivamente conscientes do seu valor; implica um conjunto de mudanças emocionais e comportamentais que diminuem a tensão nas relações pessoais.

A intervenção pedagógica em educação emocional foi considerada positiva por todos os docentes, com $90 \%$ deles afirmando que os alunos passaram a compreender mais as emoções dos demais e também as suas. Todos os docentes registraram a importância e necessidade de aprofundamento na área de educação emocional, e 91\% compreendem que essa é uma questão muito importante para o seu desenvolvimento profissional.

\section{CONSIDERAÇÕES FINAIS}

A ideia de uma educação emocional na escola parte do pressuposto de que os sistemas educacionais existentes parecem não atender satisfatoriamente às necessidades nem dos alunos, nem dos docentes, nem dos familiares, nem da escola como um todo. A insatisfação e o descontentamento são assim o primeiro movimento de busca de uma solução. Investigou-se, inicialmente, o percurso histórico da temática, recordando a importância da popularização da expressão "inteligência emocional", feita pela vendagem de um best-seller. Os estudos acadêmicos, então, entram em cena, aprofundando os conceitos e procurando aplicações eficazes. Neste caminho, é aperfeiçoada a compreensão do que seja inteligência emocional e surge a concepção de competência emocional. Uma terceira opção é por nós defendida: a vivência emocional. Esta se destaca das abordagens anteriores pela inserção do corpo, este é de fato o locus onde se dará a educação emocional. Diminui, portanto, na vivência emocional, o peso dado ao raciocínio e aos comportamentos cognitivos. O diálogo com as Práticas Integrativas e Complementares, oficialmente reconhecidas na realidade brasileira por meio de portarias ministeriais, é estabelecido.

Com este aporte teórico, passamos à descrição da experiência pioneira desenvolvida na Secretaria de Educação, no município de Queimadas, interior da Paraíba. Os docentes participaram do curso de formação em educação emocional, ministrado pelo Neemoc da Universidade Federal da Paraíba. A expectativa do curso foi não apenas a capacitação profissional para que os docentes aplicassem em sala de aula os conhecimentos aprendidos, mas, sobretudo, o trabalho feito em si mesmo, no sentido de sentirem um bem-estar pessoal, um melhor estado de equilíbrio em suas próprias emoções. Os dados analisados, a partir dos questionários e depoimentos, mostram os resultados positivos da experiência. Recordamos, à guisa de conclusão, alguns dos principais resultados obtidos: 93\% dos docentes, após o curso de formação em educação emocional, perceberam mudanças em suas próprias atitudes, ficando mais afetivos; $94 \%$ afirmaram que seus alunos passaram a confiar mais neles; $88 \%$ relataram que seus alunos desenvolveram condutas mais afetivas. Em nosso entendimento, estes dados resumidos e os demais revelam a eficácia da proposta, tanto na formação do docente quanto na aplicação destes saberes pelos próprios professores aos seus alunos. Em síntese, podemos 
afirmar que a vivência emocional-VE se constitui como uma possibilidade de intervenção metodológica no campo da educação emocional e que o diálogo estabelecido com as Práticas Integrativas e Complementares apresenta-se como um caminho importante e gerador de resultados significativos, merecendo novos estudos sobre sua relação com a aprendizagem.

\section{REFERÊNCIAS}

ALZINA, Rafael Bisquerra; GONZÁLEZ, Juan Carlos Pérez; NAVARRO, Esther García. Inteligencia Emocional en Educación. Madrid: Sintesis, 2015.

AMBRONA, Tamara; LÓPEZ-PÉREZ, Belén; MÁRQUEZ-GONZÁLEZ, María. Eficacia de un programa de educación emocional breve para incrementar la competencia emocional de niños de educación primaria. Revista Española de Orientación y Psicopedagogía, v. 23, n. 1, enero-abr., 2012. p. 39-49.

BISQUERRA, Rafael. Educación emocional y bienestar. Barcelona: Praxis, 2000.

BISQUERRA, Rafael; ESCODA, Nuria Perez. Las Competencias Emocionales. Educación XXI, v. 10, p. 61-82, 2007.

BOGDAN, Robert; BIKLEN, Sari. Investigação qualitativa em educação: uma introdução à teoria e aos métodos. Porto: Porto Editora, 1994.

BOS, Lex. Confiança, doação e gratidão: forças construtivas da vida social. São Paulo: Instituto Fonte; Associação de Pedagogia Social, 2010.

DAMÁSIO, António. A estranha ordem das coisas: a vida, os sentimentos e as culturas humanas. Lisboa: Círculo de Leitores, 2017.

FILELLA-GUIU, Gemma; PÉREZ-ESCODA, Núria; MORERA, María-Jesús; FRAGOSO-LUZURIAGA, Rocío. Inteligencia emocional y competencias emocionales en educación superior, ¿un mismo concepto? Revista Iberoamericana de Educación Superior, v. I, n. 16, 2015.

FRAGOSO, Vitor; CHAVES, Martha. Educação emocional para seniores. Viseu, Portugal: Psico \& Soma, 2012.

FRAGOSO-LUZURIAGA, Rocío. Inteligencia emocional y competencias emocionales en educación superior, ¿un mismo concepto? Revista Iberoamericana de Educación Superior, v. I, n. 16, 2015.

FREIRE, Paulo. Pedagogia da autonomia. São Paulo: Paz e Terra, 2011.

GARCIA RETANA, José Ángel. La educación emocional, su importancia en el proceso de aprendizaje. Educación, v. 36, n. 1, p. 1-24, 2012.

GATTI, Bernardete A. Formação continuada de professores: a questão psicossocial. Cadernos de Pesquisa, n. 119, p. 191-204, 2003.

GIORGI, Amedeo. Sobre o método fenomenológico utilizado como modo de pesquisa qualitativa nas ciências humanas: teoria, prática e avaliação. In: Pesquisa qualitativa: enfoques epistemológicos e metodológicos. Petrópolis: Vozes, 2014.

GONZAGA, Alessandra Rodrigues; MONTEIRO, Janine Kieling. Inteligência emocional no Brasil: um panorama da pesquisa científica. Psicologia: Teoria e Pesquisa, v. 27, n. 2, 2011, p. 225-232.

MACÊDO, Shirley Martins de. Análise fenomenológica de depoimentos escritos: apresentando e discutindo uma possibilidade. Rev. Estudos de Psicologia, PUC-Campinas, v. 16, n. 1, p. 35-44, 1999.

MAYER, John D.; SALOVEY, Peter. Que es Inteligencia Emocional? In: NAVAS, José Miguel Mestre; BERROCAL, Pablo Fernandez (coord.). Manual de Inteligencia Emocional. Madrid: Piramide, 2012.

NAVAS, José Miguel Mestre; BERROCAL, Pablo Fernandez (coord.). Manual de Inteligencia Emocional. Madrid: Piramide, 2012.

ORTS, Joan Vaello. El Profesor Emocionalmente Competente. Barcelona: Graó, 2009.

PETRIDES, K. V.; FURNHAM, A. Trait emotional intelligence: Psychometric investigation with reference to established trait taxonomies. European Journal of Personality, n. 15, 2011, p. 425-448, 2011.

POSSEBON, Elisa Gonsalves. Educação emocional: aplicações. João Pessoa: Libellus Editorial, 2018.

POSSEBON, Fabricio. Espiritualidade e saúde: a experiência grega arcaica. In: POSSEBON, Fabricio; POSSEBON, Elisa Gonsalves (org.). Ensaios sobre espiritualidade, emoções e saúde. João Pessoa: Libellus, 2017. REDORTA, Josep; OBIOLS, Meritell; BISQUERRA, Rafael. Emoción y Conflicto: aprenda a manejar las emociones. Barcelona: Paidós, 2016.

RICHARDSON, Roberto Jarry. Pesquisa Social: métodos e técnicas. São Paulo: Atlas, 2011. 


\section{\& Contexto}

Elisa Pereira Gonsalves Possebon - Fabricio Possebon

SARRIONANDIA, Ainize; GARAIGORDOBIL, Maitel. Efectos de un programa de inteligencia emocional en factores socioemocionales y síntomas psicosomáticos. Effects of an emotional intelligence program on socioemotional factors and psychosomatic symptoms. Revista Latinoamericana de Psicología, v. 49, n. 2 , p. 110-118, 2017.

SEDUC. Secretaria Municipal de Educação. Dados gerais sobre as escolas do município de Queimadas-PB. 2018.

STAKE, Robert E. Pesquisa qualitativa: estudando como as coisas funcionam. Porto Alegre: Penso, 2011. TORO, Rolando. Biodanza. Santiago: Cuarto Próprio, 2009. 